\title{
MK-801 effects on a learned food preference depends on dosage: Is it disruption of learning or a conditioned aversion?
}

\author{
NATALIE MYHAL and ALISON S. FLEMING \\ University of Toronto, Erindale College, Mississauga, Ontario, Canada
}

\begin{abstract}
Three experiments were conducted to determine the effects of the NMDA antagonist MK-801 on the acquisition of a socially mediated learned food preference. Female rats were exposed for $1 \mathrm{~h}$ to a novel smelling/tasting food applied to the snout region of an anesthetized cagemate. Prior to the exposure, different groups were injected subcutaneously with different concentrations of MK-801. Food preferences were established by determining subsequent 24- and 48-h intakes of the novel preexposed food and another novel food. MK-801, at all but the lowest concentration $(.02 \mathrm{mg} / \mathrm{kg})$, eliminated the learned food preference for the preexposed diet exhibited by uninjected controls. At the highest dose $(.08 \mathrm{mg} / \mathrm{kg})$, animals appeared to be actually avoiding the preexposed food. This interpretation was reinforced by the findings that MK- 801 does not produce reduced intake of the preexposed food if the drug is injected $2 \mathrm{~h}$ prior to the exposure. Avoidance of the preexposed diet does occur if MK-801 is injected $1 \mathrm{~h}$ after the exposure or if a different NMDA antagonist, AP-5, is infused into the ventricles. These data indicate that the conditioned aversion produced by MK- 801 may not be due to general peripheral malaise-inducing properties of the drug and that the NMDA system itself may be involved in processes associated with conditioned food aversions. At low concentrations, NMDA antagonists appear to block learning of an appetitive task, whereas, at high concentrations, they appear to facilitate processes associated with conditioned aversions.
\end{abstract}

There is growing evidence that learning is not a unitary phenomenon but that different kinds of learning are mediated by different brain regions and different neurotransmitter systems (see Morris, Kandel, \& Squire, 1988). Recent work on the involvement of the N-methyl-Daspartate (NMDA) receptors in learning and memory highlights this point (Collingridge, 1987; Cotman, Monaghan, \& Ganong, 1988; Morris, Anderson, Lynch, \& Baudry, 1986; Morris, Halliwell, \& Bowery, 1989). The NMDA receptors are normally activated by the excitatory amino acid L-glutamate and are concentrated in hippocampus, amygdala, and neocortex (Monaghan \& Cotman, 1986). The role of these receptors on plasticity and learning tasks believed to be mediated by these sites has been the focus of much of the recent work on neurochemical mediators of learning and memory.

For instance, there is substantial evidence that the NMDA antagonist, AP-5 (D-2-amino-5-phosphonopentanoic acid), whether infused into the ventricles or directly into the hippocampus, blocks the induction of long-term potentiation in CAl region (Collingridge, Kehl,

This work was supported by an operating grant from the Natural Sciences and Engineering Research Council of Canada awarded to A. S. Fleming. Many thanks to Barbara Gilstrap for typing and editorial assistance, Una Cheung for technical assistance, and Sylvie Malenfant for thoughtful discussions. Correspondence should be addressed to Alison S. Fleming, University of Toronto, Erindale College, Mississauga, Ontario L5L 1C6, Canada.
\& McClennan, 1983; Errington, Lynch, \& Bliss, 1987; Morris et al., 1986), interferes with step-through passive avoidance learning (Danysz, Wroblewski, \& Costa, 1988) and place learning in a water-maze task (Morris et al., 1986), and impairs the acquisition of a learned olfactory preference in juveniles (Lincoln, Coopersmith, Harris, Cotman, \& Leon, 1988).

Some of these effects have been replicated and extended by use of a different noncompetitive antagonist, MK-801 [(+)-5-methyl-10,11-dihydro-5H-dibenzo (a,d)cyclohepten-5,10-imine maleate], that crosses the blood-brain barrier and, hence, can be injected systemically. MK-801 not only blocks the induction of long-term potentiation (Stringer \& Guyenet, 1983) and retards acquisition of a spatial task (Malenfant, O'Hearn, \& Fleming, in press; Robinson, Crooks, Shinkman, \& Gallagher, 1989) and step-through passive avoidance learning (Bevenga \& Spaulding, 1988), it also has been shown to impair the acquisition of a conditioned odor aversion (in a tasteodor pairing paradigm; see Robinson et al., 1989). However, other forms of learning are not affected by NMDA antagonists. Morris et al. (1986) found no deficits following intraventricular AP-5 in the acquisition of a visual discrimination task. In a recent series of studies, Robinson et al. (1989) also found no impairment in the production by $\mathrm{LiCl}$ of a conditioned taste aversion when animals were injected with MK-801 immediately prior to introduction of the novel taste. 
Over the past few years, we have been studying the neurochemical bases of learning and memory within the context of species-characteristic behavior systems. Specifically, we have investigated the effects of NMDA blockers on the formation and retention of maternal memories, sexual memories, and memories for new foods within a social context. Our data suggest that the NMDA system is not involved in the acquisition of either maternal or sexual memories (Fleming \& Kučera, 1990; Malenfant et al., in press). However, within these behavioral systems, the absence of an effect of the NMDA blockers may be due to the powerful hormonal influences present during the initial elicitation of both types of behavior.

The present report focuses on the role of the NMDA system in another species-characteristic phenomenonnamely, the formation of a food preference based on the prior experience of smelling (and, possibly, tasting) a new food on the mouth region of a familiar conspecific. The learning that occurs is robust (Galef, Kennett, \& Stein, 1985; Galef \& Stein, 1985; Galef \& Wigmore, 1983; Posadas-Andrews \& Roper, 1983), is not influenced by the animal's hormonal state, and occurs as a result of simple exposure to a cagemate powdered with the new food. The learning that occurs is social in nature; it will not occur as readily if a novel food is presented in the absence of the conspecific, (Galef et al., 1985); it is a "prepared" response in the sense that it occurs if the food is placed onto the conspecific's mouth region where food odors would be expected to be found, but not if it is placed onto the animal's posterior region (Galef \& Stein, 1985). Finally, the acquisition that occurs is one-trial acquisition and is inferred by the animal's performance on retention testing rather than by evidence of changes in behavior during initial exposure.

This paper consists of three experiments. In the first, animals were preexposed for $1 \mathrm{~h}$ to an anesthetized cagemate whose mouth region had been brushed with powdered Purina Lab Chow mixed with either cinnamon or cocoa and were then provided with two food cups containing the cocoa and cinnamon diets. Intake over the next $24 \mathrm{~h}$ was monitored. Prior to exposure animals were injected with different concentrations of MK-801 or saline. The next two experiments were designed to determine whether the absence of an exposure-induced preference in the animals injected with MK-801 is due to blocking of exposure learning or, instead, is due to the production of a conditioned aversion to the preexposed new food. Strategies adopted to test this hypothesis included varying the temporal interval and order of exposure of preexposed food (CS) and drug and injecting a different NMDA antagonist.

The results of these studies raise the possibility that, for some behaviors that have been studied, the NMDA blockers (at the high concentrations) may not be acting directly on a learning system but, rather, they may retard acquisition by producing a low-level malaise and thus a conditioned avoidance of the preexposed food.

\section{EXPERIMENT 1}

\section{Method}

Subjects and Housing. The subjects were 60-90-day-old virgin female Sprague-Dawley female rats, bred at Erindale College, University of Toronto, from a stock obtained from the Charles River Breeding Farms in St. Denis, Quebec. The animals were housed in pairs in $37 \times 47 \times 21 \mathrm{~cm}$ transparent Plexiglas cages and maintained under a 12:12-h illumination cycle, with lights on at $0800 \mathrm{~h}$. Prior to the experimental procedure the animals had ad-lib access to Purina Lab Chow and water.

Experimental diets. The cocoa diet (COC) consisted of powdered Purina Lab Chow adulterated with ( $2 \%$ by weight) unsweetened Hershey's cocoa. The cinnamon (CIN) diet consisted of powdered Purina Lab Chow adulterated with ( $1 \%$ by weight) Club House ground cinnamon.

Procedure. Seventy-five observer-demonstrator pairs were divided into six groups. Within five of these groups, the observer animals were preexposed to either CIN or COC diets (dusted onto the demonstrators' snout regions) and were injected with either saline $(0 \mathrm{mg} / \mathrm{kg}, n=21)$ or different concentrations of MK-801 $(.02 \mathrm{mg} / \mathrm{kg}, n=10 ; .04 \mathrm{mg} / \mathrm{kg}, n=10 ; .06 \mathrm{mg} / \mathrm{kg}, n=10 ;$ $.08 \mathrm{mg} / \mathrm{kg}, n=17$ ). The sixth (control) group was not preexposed to a novel food $(n=7)$.

All groups were provided with ad-lib access to the powdered $\mathrm{Pu}$ rina Lab Chow for 4 days prior to exposure to the novel foods. Food was removed on the evening before the exposure condition so that, at the time of exposure, the animals were 21-h fooddeprived. On the day of exposure, pairs of animals were separated and the demonstrator animals (DEMs) were anesthetized with atravet $(.085 \mathrm{ml} / 100 \mathrm{~g}$ of $10 \mathrm{mg} / \mathrm{ml})$ and ketamine $(.15 \mathrm{ml}$ of $100 \mathrm{mg} / \mathrm{ml})$. Each DEM had its snout rolled three times in a jar containing either CIN or COC diet. The DEM then was returned to the home cage behind the wire mesh divider, with the snout placed into an opening in the divider. The opening was round, $4.5 \mathrm{in}$. in diameter and covered with .5-in. wire mesh. The observers (OBs) were injected with either $0.9 \%$ saline or varying doses of $\mathrm{MK}-801$ in $.1 \mathrm{ml} / \mathrm{kg}$ and, 15 min later, were placed into their home cages on the other side of the divider.

The OBs were allowed $1 \mathrm{~h}$ of exposure to the anesthetized DEM, after which each DEM was removed and placed back into a new cage. The partition was removed from the home cage and, after a 1 -h interval, two food jars were placed into right and left front quadrants of the cage. One jar contained the CIN diet; the other contained the COC diet. The position of each food type was counterbalanced. To record food intakes, the two food jars were weighed to the nearest $0.1 \mathrm{~g}$ at 0 and $24 \mathrm{~h}$ after introduction into the cage. All spilled food was collected and weighed. To ensure that only food was being weighed and not nesting material or fecal pellets, the food was strained through a sieve prior to weighing. Analyses were undertaken on intake of the two diets during the first $24-\mathrm{h}$ periods.

\section{Results and Discussion}

Control animals not preexposed to a novel food exhibit no preference when novel foods are presented, eating approximately $46 \%$ of one food (CIN) and $54 \%$ of the other (COC). Consistent with this, using the binomial test, there were no differences in the number of animals preferring one food over another. However, as shown in Figure 1, when animals are preexposed to a new food, they develop a preference for that food over another novel diet, such that the ratio in favor of the preexposed food shifts to approximately $64 \%$ (regardless of whether the preexposed 


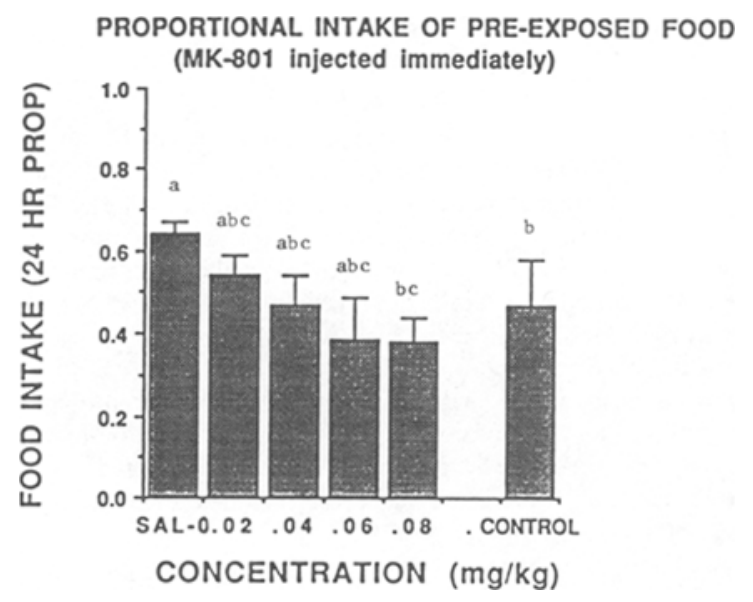

Figure 1. Proportional intake of the preexposed food over the first $24 \mathrm{~h}$ in animals receiving different concentrations of MK-801 immediately prior to the exposure phase. (Proportional intake $=$ grams preexposed diet/grams of preexposed + novel diets.) Groups not sharing a superscript differ significantly.

food is CIN or COC). Binomial tests indicate that significantly more of the preexposed saline group preferred the preexposed food over the alternate food $(86 \%$ vs. $14 \%, p<.001)$. Comparisons were made between the saline-exposed animals $(0 \mathrm{mg} / \mathrm{kg}$ for CIN and COC groups combined) and nonexposed control animals in the proportional intake (amount ingested of the preexposed food [or of either the CIN or COC for controls]/amount ingested of both foods) over the first $24 \mathrm{~h}$ periods. All analyses of variance were undertaken on the log transforms of the proportional measures. Not surprisingly, saline-exposed animals ingested significantly more of the preexposed food than did the controls $[F(1,26)=5.7$, $p<.02]$.

As can be seen in Figure 1, within the five preexposed groups there was a clear dose-response relation in the effectiveness of MK-801 in blocking the learned preference and a significant difference among the six groups (including the nonexposed group) for the 24 -h intakes $[F(5,74)=$ $3.9, p<.004]$. Post hoc Scheffé comparisons across all six groups showed a significant difference between the extreme dosages $(0 \mathrm{mg} / \mathrm{kg}$, saline, and $.08 \mathrm{mg} / \mathrm{kg})$; Group $.08 \mathrm{mg} / \mathrm{kg}$ ate proportionately less of the preexposed than did saline animals. Other groups at intermediate concentrations did not differ from one another or from extreme groups; they also did not differ from the nonexposed control group.

Although these data suggest that MK-801 effectively blocks the learned preference and that animals respond to the two diets no differently than do naive animals for whom both diets are entirely novel, further analyses of these data indicates that at the highest concentration, at least, animals may be experiencing some malaise and are, possibly, showing a conditioned aversion to the preexposed food. For instance, in the analysis of total food intake, there was a significant overall difference among the six groups $[F(5,75)=6.2, p<.001]$. On the basis of post hoc Scheffé tests, the animals in the MK-801 $.08 \mathrm{mg} / \mathrm{kg}$ group ate significantly less during the first $24 \mathrm{~h}$ than did Group $.02 \mathrm{mg} / \mathrm{kg}$, Group $.04 \mathrm{mg} / \mathrm{kg}$, Group $.06 \mathrm{mg} / \mathrm{kg}$, and the nonexposed control group.

Moreover, when each group was analyzed separately for the relative intake of the two diets (preexposed vs. novel), there were no differences within MK-801 Group $.02 \mathrm{mg} / \mathrm{kg}$, Group $.04 \mathrm{mg} / \mathrm{kg}$, and Group $.06 \mathrm{mg} / \mathrm{kg}$, or in the nonpreexposed control group. However, there were differences in both the saline $(0 \mathrm{mg} / \mathrm{kg})$ and the $.08 \mathrm{mg} / \mathrm{kg}$ groups. The saline animals ate significantly more of the preexposed diet than the novel diet (binomial, $p<.05$ ), whereas the $.08 \mathrm{mg} / \mathrm{kg}$ group showed the reverse pattern, eating significantly more of the novel diet than the preexposed diet (binomial, $p<.002$ ).

Since, in this analysis, the intermediate-dose MK-801 groups did not show the preference for the preexposed food demonstrated by the saline animals, the drug seems to be blocking the conditioned preference learning. Since the $.08 \mathrm{mg} / \mathrm{kg}$ group did not exhibit the same pattern of response as that shown by either the lower dose groups or the nonexposed controls, high concentrations of the drug probably also produce a conditioned aversion.

\section{EXPERIMENT 2}

To determine whether the drug, MK-801, is in fact producing an aversion over and above an effect of blocking memory, in Experiment 2, we injected animals with the drug either $1 \mathrm{~h}$ after the exposure or $2 \mathrm{~h}$ before the exposure period. By injecting $1 \mathrm{~h}$ after the exposure, we reasoned that, if the drug is producing an aversion, it should be able to reproduce the results of Experiment 1 (e.g., of both eliminating the exposure-induced preferences and producing a preference for the novel diet) even though the hypothesized sickness does not occur until $1 \mathrm{~h}$ after the exposure period. Also, since the drug is being injected after the exposure period, blocking effects on acquisition of the preference clearly could not occur. The possibility that the postlearning injection could disrupt the consolidation of the learned preference is unlikely; most studies in which NMDA blockers are given either before or after learning show that learning is blocked if the drug precedes the learning but not if the learning precedes the drug (Danysz et al., 1988; Malenfant et al., in press; Patterson, Scharre, Bennett, \& Rosenzweig, 1988; however, see Bevenga \& Spaulding, 1988).

By injecting $2 \mathrm{~h}$ before the exposure in a backwards conditioning paradigm, we reasoned that if the $.08 \mathrm{mg} / \mathrm{kg}$ continues to eliminate the exposure-induced preference and does not produce a preference for the alternate novel diet, then the underlying mechanism is not a conditioned aversion, since such conditioning is considerably weaker when the reinforcer (e.g., the drug) precedes the CS (e.g., novel food) (Siegel \& Domjan, 1971). On the basis of known side effects of the drug (like head swaying and wobbling), the temporal course of MK-801 effectiveness 
is still present $2 \mathrm{~h}$ after injection. Although the time course of motoric, aversive, and acquisition-blocking effects of the drug may not be identical, one assumes a higher threshold for the motoric side effects than for its other effects.

\section{Method}

The procedures were essentially identical to those in Experiment 1 , with a few exceptions. The animals received injections of MK-801 or saline either $1 \mathrm{~h}$ after or $2 \mathrm{~h}$ before the preexposure period (rather than immediately before) and, for the groups injected after the exposure, the two food jars were not placed into the cage for testing until $1700 \mathrm{~h}$ (rather than $1400 \mathrm{~h}$ ). However, in both Experiments 1 and 2, the food test was initiated $3 \mathrm{~h}$ after the injections. Finally, unlike in Experiment 1, in this experiment all preexposed groups were exposed to the CIN diet; none were exposed to the COC diet.

Eight groups of animals were tested; these included one group of animals that received no preexposure $(n=9)$ and five groups that were injected $1 \mathrm{~h}$ after the end of the $1-\mathrm{h}$ exposure period with different concentrations of MK-801, including saline $0 \mathrm{mg} / \mathrm{kg}(n$ $=11), .02 \mathrm{mg} / \mathrm{kg}(n=5), .04 \mathrm{mg} / \mathrm{kg}(n=5), .06 \mathrm{mg} / \mathrm{kg}(n=$ $5)$, and $.08 \mathrm{mg} / \mathrm{kg}(n=10)$. The last two groups were injected with either saline $0 \mathrm{mg} / \mathrm{kg}(n=6)$ or $.08 \mathrm{mg} / \mathrm{kg} \mathrm{MK}-801 \quad(n=$ 8) $2 \mathrm{~h}$ before the exposure period. Analyses evaluating the dose-response relation involved a one-way ANOVA, comparing the five groups injected after the exposure and the nonexposed control group. The second analysis evaluated the effects of injection time (before vs. after) and drug level $(0 \mathrm{mg} / \mathrm{kg}$ vs. $.08 \mathrm{mg} / \mathrm{kg})$ in a 2 (time) $\times 2$ (drug) ANOVA. These analyses were followed by post hoc Scheffé tests.

\section{Results and Discussion}

Consistent with our earlier results, when the animals receive no preexposure (nonexposed controls), they exhibited no preference between the two diets in the proportion of total food intake: The animals consumed approximately .54 of the COC diet and .46 of the CIN diet. Also, the animals that were preexposed and injected with saline exhibited a preference for the preexposed diet, consum-

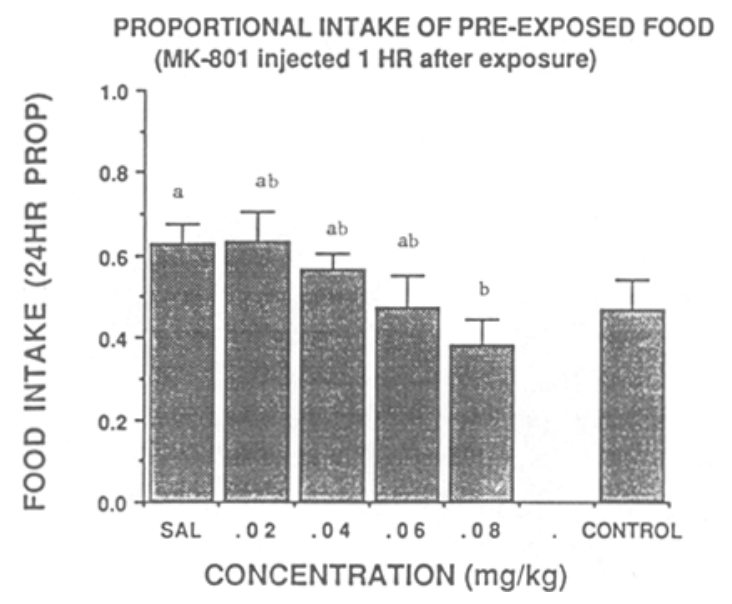

Figure 2. Proportional intake of the preexposed food over the first $24 \mathrm{~h}$ in animals injected with different concentrations of MK-801 $1 \mathrm{~h}$ after the exposure period. Groups not sharing a superscript differ significantly.
PROPORTIONAL INTAKE OF PRE-EXPOSED FOOD

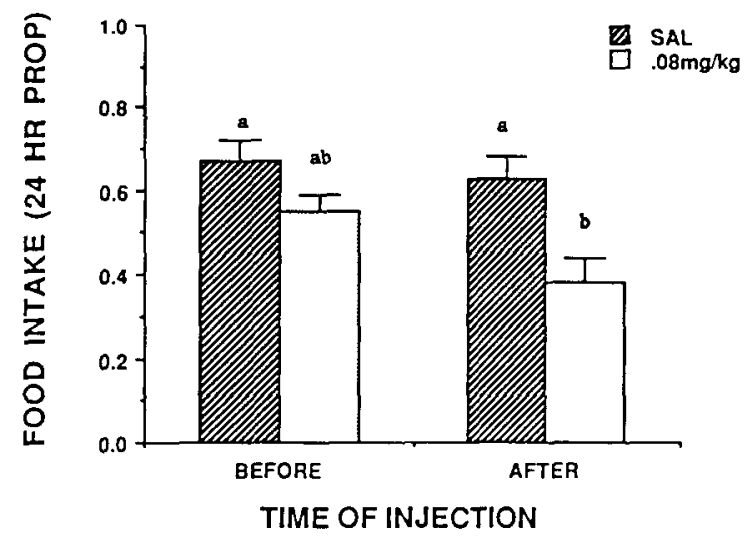

Figure 3. Proportional intake of the preexposed food over the first $24 \mathrm{~h}$ in animals receiving SAL or MK-801 at the high $.08 \mathrm{mg} / \mathrm{kg}$ dose injected $2 \mathrm{~h}$ before or $1 \mathrm{~h}$ after the exposure period. Groups not sharing a superscript differ significantly.

ing approximately .63 of their total diet as the preexposed food. Seventy-seven percent of the animals preferred the preexposed diet; $23 \%$ preferred the normal diet (binomial, $p=.08$, one-tailed). No such preference was exhibited by the unexposed group.

As shown in Figure 2, there was a clear dose-response relation. There was a significant difference among the groups in proportional 24-h intakes of the preexposed diet $[F(5,44)=2.8, p<.03]$. Again, post hoc tests indicated that the only significant difference was between Group $.08 \mathrm{mg} / \mathrm{kg}$ and the saline controls. The $.08 \mathrm{mg} / \mathrm{kg}$ animals ate significantly less of the preexposed diet than did the saline group. There were no differences between the three middle MK-801 groups. Again, the $.08 \mathrm{mg} / \mathrm{kg}$ animals ate less of the preexposed diet than did the other groups.

Also, for the $.08 \mathrm{mg} / \mathrm{kg}$ group, $78 \%$ of the animals preferred the novel diet, whereas only $23 \%$ preferred the preexposed diet (binomial, $p=.08$, one-tailed). Binomial tests of proportions of animals preferring one diet over another showed no significant preferences in groups injected with $.02 \mathrm{mg} / \mathrm{kg}, .04 \mathrm{mg} / \mathrm{kg}$, or $.06 \mathrm{mg} / \mathrm{kg}$. These groups, therefore, neither showed a preference for the novel diet, as shown by Group $.08 \mathrm{mg} / \mathrm{kg}$, nor a preference for the preexposed diet, as shown by the saline controls. In this respect, they resembled the nonexposed group. There were no group differences for total 24-h intakes.

The second set of analyses concerned with injection time and drug effects indicates that for the $24-\mathrm{h}$ proportional intakes, the saline groups ate significantly more of the preexposed diet than did the $.08 \mathrm{mg} / \mathrm{kg}$ MK- 801 groups $[F(1,31)=6.2, p<.02]$ (see Figure 3 ). In addition to a main drug effect, as can be seen in Figure 3, there was also a main effect of time of injection. The animals injected after the exposure ate significantly less of the preexposed diet than did the animals injected before $[F(1,31)$ $=3.9, p<.05$ ]. 
Post hoc tests indicate that the group that ate the least of the preexposed diet in all the analyses was the $.08 \mathrm{mg} / \mathrm{kg}$ group injected after the exposure. This group ate proportionately less than did both saline groups but did not differ significantly from the $.08 \mathrm{mg} / \mathrm{kg}$ group injected prior to exposure. Other groups did not differ from one another.

Binomial tests to determine the proportion of animals exhibiting a preference for the preexposed diet in each of the four groups indicated that the two saline groups each exhibited a significant preference for the preexposed diet $(88 \%$ vs. $18 \%, p=.06$, and $78 \%$ vs. $22 \%, p=$ .08 ). Also, consistent with the notion that MK-801 at high concentrations produces a conditioned aversion, the animals injected prior to the exposure-when conditionedaversion effects should not be seen-showed no aversion to the preexposed diet (66\% vs. $33 \%$ in favor of the preexposed food), whereas the MK-801 group injected after exposure clearly did $(22 \%$ vs. $78 \%$ in favor of the novel diet, $p=.08$ ).

These results indicate that MK-801 at high concentrations can produce a conditioned aversion and that a preference for the novel diet over the preexposed diet will occur if the drug is injected coincident with or following a period of exposure learning. As predicted by the observation that a conditioned aversion should not occur in the backwards conditioning paradigm, a preference for the novel diet does not occur if the drug is injected substantially prior to the exposure period-although the drug's effects are still occurring at the time of the exposure. However, the fact that the animals receiving the drug prior to exposure also did not exhibit the strong preference for the preexposed diet shown by the saline control animals suggests that MK-801 at high concentrations also possesses some of the acquisition-blocking effects produced by lower concentrations of the drug.

\section{EXPERIMENT 3}

In Experiment 3, we investigated the effects of a different NMDA blocker on the acquisition of a food preference. In this case, we infused the competitive receptor blocker AP-5 (or saline) directly into the lateral ventricles $30 \mathrm{~min}$ before preexposure to the novel food. Either 7.5 or $9.5 \mu$ l of AP-5 (DL-2-amino-5-phosphonovaleric acid) was infused over a period of $1 \mathrm{~min}$. To permit time for the ether effects to abate, the exposure occurred 30 min after the drug; side effects of the AP-5 were still apparent at this time. In all other respects, the procedures were identical to that of Experiment 1.

\footnotetext{
Method

Using stereotaxic surgery, all animals were implanted with cannulae directed at the left lateral ventricle (coordinates: $\mathrm{AP}=-.20$, $\mathrm{ML}=+1.7, \mathrm{~V}=-3.0$ ). Two to four weeks after surgery, the animals were placed into the experimental paradigm. Thirty minutes before the exposure phase, the animals were lightly anesthetized with ether and injected intraventricularly with either $7.5 \mu \mathrm{l}$ of AP$5(n=7), 9.5 \mu$ l AP-5 $(n=9)$, or saline $(n=2)$. All animals
}

were given a preexposure to the CIN diet (none were preexposed to $\mathrm{COC}$ ).

\section{Results}

As shown in Figure 4, there were overall group differences in the proportional 24-h intakes $[F(2,17)=4.0$, $p<.04$ ]. Post hoc tests showed that Group $7.5 \mu \mathrm{l}$ ate less than did the saline groups. Finally, in both AP-5 groups, a significantly higher proportion of animals ate the alternate novel diet than the preexposed diet $(7.5 \mu \mathrm{l}$ : $100 \%$ in favor of the novel diet, $p<.003 ; 9.5 \mu \mathrm{l} ; 86 \%$ in favor of the novel diet, $p<.06$, one-tailed).

\section{GENERAL DISCUSSION}

Consistent with the findings of Galef and his colleagues (Galef, Kennett, \& Stein, 1985; Galef \& Stein, 1985; Galef \& Wigmore, 1983), the results of these experiments indicate that animals develop a preference for a new food if they have had prior exposure to that food (in which they can smell and/or taste it) when it has been applied to the mouth region of an anesthetized conspecific.

These studies show further that this learned food preference can be eliminated by systemic injections of the drug MK-801, an anticonvulsant that disrupts NMDA function. The decision to use this drug was based on the observations that MK- 801 blocks the acquisition of a number of learning tasks normally mediated by the hippocampus (Robinson et al., 1989), including food-preference learning (Winocur, in press). Also, MK-801 is easier to work with than are some of the other competitive NMDA blockers, because it crosses the blood-brain barrier and, hence, can be injected systemically.

Although it is tempting to conclude that food-preference learning, like some other forms of olfactory learning (Lincoln et al., 1988), is mediated by the NMDA system, our data suggest that at the higher concentrations of the drug

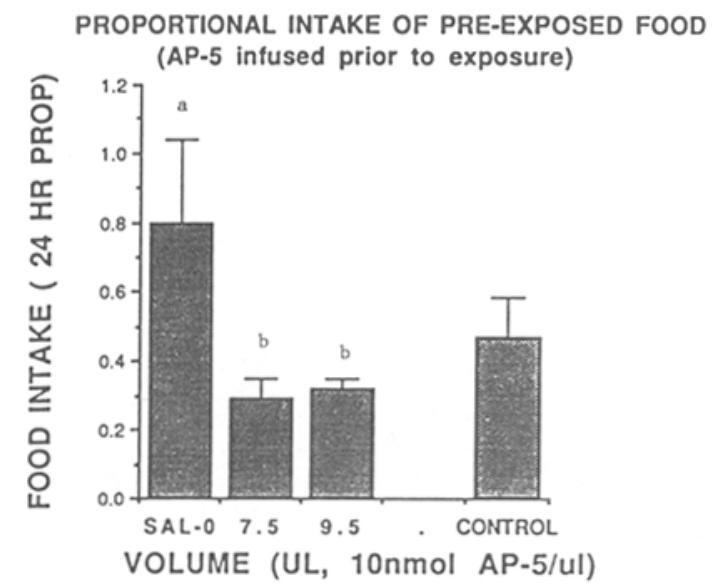

Figure 4. Proportional intake of preexposed food over the first $24 \mathrm{~h}$ in animals receiving intraventricular infusions of AP-5 into the lateral ventricles. AP-5 given in two volumes $(7.5 \mu \mathrm{l}$ and $9.5 \mu \mathrm{l})$. Groups not sharing a superscript differ significantly. 
(e.g., .08 mg/kg) some form of conditioned odor and/or taste-aversion learning may also be occurring. This conclusion is based on the findings that the animals receiving the higher concentration at the time of the food exposure did not behave like inexperienced animals, but instead they ate less of the preexposed food than did the inexperienced controls; moreover, a significant proportion of the animals within the group developed a preference for the novel diet over the preexposed diets. The injected animals also reduced their total food intake, indicating some sort of malaise. In addition, the highest dose was able to eliminate the learned food preference when the drug was administered considerably after the learning had occurred; lower doses did not have this effect. These results are consistent with the known effectiveness of a prolonged CS-US interval in conditioned taste-aversion learning (Revusky \& Garcia, 1970). Moreover, the fact that NMDA blockers tend to be most effective when administered prior to learning and either ineffective or considerably less effective when administered after learning (Danysz et al., 1988; Malenfant et al., in press; Patterson et al., 1988) suggests that any blocking effects produced by the delayed injection are not due to the disruption of learning or memory of the preexposed food.

The second test of the conditioned-aversion interpretation was to include backwards conditioning groups, in which the drug preceded the exposure by a few hours. With conditioned taste aversion, sickness (US) must follow, not precede, the novel food (CS). In our situation, the NMDA-blocking effects of the drug, and, hence, its potential effectiveness in retarding acquisition of the new food learning, are presumably still present $2 \mathrm{~h}$ after the injection when the exposure occurs (since motor side effects are present at this time). The fact that, in this situation, the high dose had the effect of preventing a preference for the preexposed diet but did not produce a preference for the alternate, novel, diet indicates that when the drug is injected at the time of the exposure or after the exposure, the strong blocking effect of the high dose is very likely due to its ability both to block acquisition of a food preference and to produce a conditioned aversion. This conclusion is supported by a study by Jackson and Sanger (1989) in which they found that a high concentration of MK-801 that produced ataxia and other side effects was able to produce a conditioned aversion when the drug was administered after a novel saccharin drink. However, these investigators did not find a dose-response relation between drug concentrations and extent of conditioned aversion. In their study, using male rats, concentrations of MK-801 of $0.1 \mathrm{mg} / \mathrm{kg}$ or lower were entirely without effect.

Other studies have also noted disruptive side effects when using high doses of MK-801. These effects are summarized by Robinson et al. (1989) and include "generalized changes in sensorimotor function, such as hyperlocomotion, repetitive sniffing, swaying, and a loss of equilibrium ... as well as performance changes that could indicate motivational impairments" (p. 163). Although these investigators do not mention malaise as one of the side effects, in one of their pilot studies they do mention reduced consummatory behavior.

On the basis of our data, we do not know whether the conditioned aversion is due to a specific effect on the NMDA system or to some more general effect of the drug. The findings of Experiment 3 showing a conditioned aversion following intraventricular infusion of the competitive NMDA antagonist AP-5 suggest that the effect might be through the NMDA system directly. This drug alters NMDA function by an entirely different mechanism than does MK-801 or the other noncompetitive blockers that apparently also produce conditioned taste aversions (Jackson \& Sanger, 1989).

These findings raise the issue as to whether the blocking effects of lower doses of MK-801 are due to druginduced deficits in learning or to a weak conditioned aversion. Although we do not know conclusively, the fact that, at these doses (e.g., .04 and $.06 \mathrm{mg} / \mathrm{kg}$ ), the animals receiving the preexposure did not differ from the inexperienced animals in their intake patterns and did not exhibit a reduced total food intake indicates that they were probably not experiencing drug-induced malaise. Consistent with this interpretation of the effects of low doses of MK-801 are the findings that, in males, $.05 \mathrm{mg} / \mathrm{kg} \mathrm{MK}$ 801 does not enhance the effects of $\mathrm{LiCl}$ in a conditioned taste- and taste/odor-aversion paradigm (Robinson et al., 1989); in fact, it blocks the suppressive effects of $\mathrm{LiCl}$ on an odor test in a conditioned taste/odor-aversion task (Robinson et al., 1989). Moreover, Jackson and Sanger (1989) found that lower doses of MK-801 were unable to produce a conditioned taste aversion.

Taken together, these studies suggest that the development of diet preferences through social learning is mediated by the NMDA system. The NMDA antagonist MK801 is able to prevent the learning if it is administered in low concentrations. However, if it is administered in high concentrations either immediately before or $1 \mathrm{~h}$ after the learning episode, it produces a strong conditioned aversion to the new food. On the basis of these results, as well as those reported by Jackson and Sanger (1989) and Robinson et al. (1989), it appears that the NMDA antagonists are not able to block the learning of a conditioned taste aversion and, in fact, they may promote this form of learning.

\section{REFERENCES}

Bevenga, M. J., \& Spaulding, T. C. (1988). Amnesic effect of the novel anticonvulsant MK-801. Pharmacology, Biochemistry \& Behavior, 30, 205-207.

Collingridge, G. (1987). The role of NMDA receptors in learning and memory. Nature, 330, 604-605.

Collingridge, G. L., Kehl, G. L., McClennan, H. (1983). Excitatory amino acids in synaptic transmission in the Schaffer collateralcommissural pathway of the rat hippocampus. Journal of Physiology, 334, 33-46.

Cotman, C. W., Monaghan, D. T., \& Ganong, A. H. (1988). Excitatory amino acid neurotransmission: NMDA receptors and HebbType synaptic plasticity. Annual Review of Neuroscience, 11, 61-80. Danysz, W., Wroblewski, J. T., \& Costa, E. (1988). Learning im- 
pairment in rats by $\mathrm{N}$-methyl-D-aspartate receptor antagonists. Neuropharmacology, 27, 653-656.

Errington, M. L., Lynch, M. A., \& Bliss, T. V. P. (1987). Longterm potentiation in the dentate gyrus: Induction and increased glutamate release are blocked by $\mathrm{D}(-)$ amino phosphonovalerate. Neuroscience, 20, 279-284.

Fleming, A. S., \& Kučera, C. (1990). Sexual memories are blocked by protein-synthesis inhibitors but not by NMDA antagonists. Manuscript submitted for publication.

Galef, B. G., KennetT, D. J., \& Stein, M. (1985). Demonstrator influence on observer diet preference: Effects of simple exposure and presence of a demonstrator. Animal Learning \& Behavior, 13, 25-30.

GALEF, B. G., \& STEIN, M. (1985). Demonstrator influence on observer diet preference: Analysis of critical social interactions and olfactory signals. Animal Learning \& Behavior, 13, 31-38.

GALEF, B., WigmoRE, S. W. (1983). Transfer of information concerning distant food: A laboratory investigation of the "informationcentre" hypothesis. Animal Behaviour, 31, 748-758.

JACKSON, A., SANGER, D. J. (1989). Conditioned taste aversions induced by phencyclidine and other antagonists of N-methyl-D-aspartate. Neuropharmacology, 28, 459-464.

Lincoln, J., Coopersmith, R., Harris, E. W., Cotman, C. W., \& LEON, M. (1988). NMDA receptor activation and early olfactory learning. Developmental Brain Research, 39, 309-312.

Malenfant, S., O'Hearn, S., Fleming, A. S. (in press). Effects of the NMDA-blocker, MK-801, on the retention of maternal behavior in postpartum rats. Physiology \& Behavior.

Monaghan, D. T., \& Cotman, C. W. (1986). Distribution of NMDAsensitive L-3H-glutamate binding sites in rat brain as determined by quantitative autoradiography. Joumal of Neuroscience, 5, 2909-2919.

Morris, R. G. M., ANderson, E., LyNCh, G. S., BAudry, M.
(1986). Selective impairment of learning and blockade of long-term potentiation by an N-methyl-D-aspartate receptor antagonist, AP5. Nature, 319, 774-776.

Morris, R. G. M., Halliwell, R. F., Bowery, N. (1989). Synaptic plasticity and learning II: Do different kinds of plasticity underlie different kinds of learning? Neuropsychologia, 27, 41-59.

MorRIS, R. G. M., KANDEL, E. R., \& SQuire, L. R. (1988). The neuroscience of learning and memory: Cells, neural circuits and behavior. Trends in Neurosciences, 11, 125-127.

Patterson, T. A., Scharre, K., Bennett, E. L., \& Rosenzweig, M. R. (1988). Influence of AP5 on memory formation in the chick. Society for Neuroscience Abstracts, 101, 10.

Posadas-ANDrews, A., \& Roper, T. J. (1983). Social transmission of food preferences in adult rats. Animal Behaviour, 31, 265-271.

RevUSKY, S. H., \& GARCIA, J. (1970). Learned associations over long delays. In G. H. Bower \& J. T. Spence (Eds.), Psychology of learming and motivation (Vol. 4, pp. 1-84). New York: Academic Press.

Robinson, G. S., Crooks, G. B., Shinkman, P. G., \& Gallagher, M. (1989). Behavioral effects of MK-801 mimic deficits associated with hippocampal damage. Psychobiology, 17, 156-164.

SIEGEL, S., \& DomuN, M. (1971). Backward conditioning as an inhibitory procedure. Learning \& Motivation, 2, 1-11.

STRINGER, J. L., \& GuYENET, P. G. (1983). Elimination of long-term potentiation in the hippocampus by phencyclidine and ketamine. Brain Research, 379, 159-164.

WinOcur, G. (in press). Anterograde and retrograde amnesia in rats with dorsal hippocampal or dorsomedial thalamic lesions. Behavioral Brain Research.

(Manuscript received May 22, 1990; revision accepted for publication August 8, 1990.) 